\title{
The L-type calcium channel Cav1.3 is required for proper hippocampal neurogenesis and cognitive functions
}

Julia Marschallinger ${ }^{1,2}$, Anupam Sah $^{3}$,Claudia Schmuckermair ${ }^{3}$, Michael Unger ${ }^{1,2}$, Peter Rotheneichner ${ }^{2,4}$, Maria Kharitonova $^{3}$, Alexander Waclawiczek ${ }^{1,2}$, Philipp Gerner $^{1,2}$, Heidi Jaksch-Bogensperger ${ }^{1,2}$, Stefan Berger ${ }^{5}$, Jörg Striessnig ${ }^{3}$, Nicolas Singewald ${ }^{3}$, Sebastien Couillard-Despres ${ }^{2,4,}$, Ludwig Aigner ${ }^{1,2,{ }^{*}}$

1: Institute of Molecular Regenerative Medicine, Paracelsus Medical University, Salzburg, Austria

2: Spinal Cord Injury and Tissue Regeneration Center Salzburg (SCI-TReCS), Paracelsus Medical University, Salzburg, Austria

3: Department of Pharmacology and Toxicology, Institute of Pharmacy and CMBI, Leopold-Franzens-University of Innsbruck, Innsbruck, Austria

4: Institute of Experimental Neuroregeneration, Paracelsus Medical University, Salzburg, Austria

5: Department of Molecular Biology, Central Institute of Mental Health and Medical Faculty Mannheim, Heidelberg University, Mannheim, Germany

*: shared senior authorship

Correspondence:

Ludwig Aigner, PhD, Institute of Molecular Regenerative Medicine, Paracelsus Medical University, Strubergasse 21, 5020 Salzburg, Austria, Tel: +43 (0)662 242080 800, Fax: +43 (0)662 2420 80809, e-mail: ludwig.aigner@pmu.ac.at 
Running title: Cav1.3 modulates hippocampal neurogenesis and spatial memory

Keywords: cacna1D, adult neurogenesis, calcium channels, neuronal differentiation, cognition

Research Highlights:

- Cav1.2 and Cav1.3 are differentially expressed in the adult neurogenic niche

- Adult neurogenesis is impaired in Cav1.3 knockout animals

- Cognition is impaired in Cav1.3 knockout animals 


\section{Disclosure:}

This manuscript is the peer-reviewed version of the article Marschallinger J, Sah A, Schmuckermair C, Unger M, Rotheneichner P, Karithonova M, Waclawiczek A, Gerner P, Jaksch-Bogensperger H, Berger S, Striessnig J, Singewald N, Couillard-Despres S, Aigner L. (2015). The L-type calcium channel Cav1.3 is required for proper hippocampal neurogenesis and cognitive functions. Cell Calcium 58(6):606-16. doi: 10.1016/j.ceca.2015.09.007. Epub 2015 Oct 3.

The final publication is available at:

http://www.sciencedirect.com/science/article/pii/S0143416015001517. 


\section{Abstract}

L-type voltage gated $\mathrm{Ca}^{2+}$ channels (LTCCs) are widely expressed within different brain regions including the hippocampus. The isoforms Cav1.2 and Cav1.3 have been shown to be involved in hippocampus-dependent learning and memory, cognitive functions that require proper hippocampal neurogenesis. In vitro, functional LTCCs are expressed on neuronal progenitor cells, where they promote neuronal differentiation. Expression of LTCCs on neural stem and progenitor cells within the neurogenic regionsin the adult brain in vivo has not been examined so far, and a contribution of the individual isoforms Cav1.2 and Cav1.3 to adult neurogenesis remained to be clarified. To reveal the role of these channels we first evaluated the expression patterns of Cav1.2 and Cav1.3 in the hippocampal dentate gyrus and the subventricular zone (SVZ) in adult (2- and 3-month old)and middle-aged (15-month old) mice on mRNA and protein levels. We performed immunohistological analysis of hippocampal neurogenesis in adult and middle-aged Cav1.3 $3^{-/}$mice and finally addressed the importance of Cav1.3 for hippocampal function by evaluating spatial memory and depression-like behavior in adult Cav1.3 $3^{-/-}$mice. Our results showed Cav1.2 and Cav1.3 expression at different stages of neuronal differentiation. While Cav1.2 was primarily restricted to mature $\mathrm{NeuN}^{+}$granular neurons, Cav1.3 was expressed in Nestin ${ }^{+}$neural stem cells and in mature $\mathrm{NeuN}^{+}$granular neurons. Adult and middle-aged Cav1.3/- mice showed severe impairments in dentate gyrus neurogenesis, with significantly smaller dentate gyrus volume, reduced survival of newly generated cells, and reduced neuronal differentiation. Further, Cav1.3 $3^{-/}$ mice showed impairment in the hippocampus dependent object location memory test, implicating Cav1.3 as an essential element for hippocampus-associated cognitive functions. Thus, modulation of LTCC activities may have a crucial impact on neurogenic responses and cognition, which should be considered for future therapeutic administration of LTCCs modulators. 


\section{Introduction}

L-type calcium channels (LTCCs) represent a subfamily of voltage gated $\mathrm{Ca}^{2+}$ channels that are characterized by high sensitivity to dihydropyridine $\mathrm{Ca}^{2+}$ channel blockers. They regulate a number of physiological functions, including the control of muscle contraction, hormone secretion and cardiac function, and LTCC antagonists are well-established drugs to treat antiarrhythmics and antihypertensives in cardiovascular diseases [1-3].In the CNS, the predominant LTCC isoforms are Cav1.2 and Cav1.3, which show widespread expression in several brain regions, such as the cerebral cortex, amygdala, cerebellum, and hippocampus [4-6]. L-type $\mathrm{Ca}^{2+}$ currents regulate neuronal excitability [7], synaptic plasticity [8, 9] and neuronal gene transcription [10]. Concerning the latter, elevated intracellular free $\mathrm{Ca}^{2+}$ concentrations trigger the transcription of genes associated with long-term changes in synaptic plasticity, cell proliferation, programmed cell death, and neuronal differentiation [1114].

Brain LTCCs are required for normal fear-, anxiety-, and depression-like behaviors[3, 15-18], and play an important role in hippocampus-dependent cognitive performance. Several studies reported an impact of Cav1.2 and Cav1.3 on hippocampus-associated learning and memory function, however with controversial findings. Administration of LTCC antagonists has been demonstrated to improve spatial memory in rodents $[19,20]$, but has also been shown to impair learning and memory performance [21, 22]. Cav1.2 knockout animals display deficits in spatial learning in the Morris water maze [8]. Cav1.2 dependent changes in cognition are primarily related to changes in LTP [8], whereas the low-voltage activated Cav1.3 channels apparently function as modulators of neuronal spiking behavior[23, 24]. Yet, the role of LTCCs in learning and memory function, in particular the individual contribution of Cav1.2 and Cav1.3 and the underlying mechanisms of LTCC-induced changes in hippocampus-dependent cognitive skills, still remains to be deciphered. 
A possible mechanism of LTCC-mediated effects on learning and memory might involve adult neurogenesis. Adult hippocampal neurogenesis, i.e. the generation of new neurons from proliferating neural stem (NSCs) and neural progenitor cells (NPCs) within the dentate gyrus of most mammals including humans [25-28], has specific functions in learning and memory, especially in spatial cognition and pattern separation $[3,29,30]$. The fact that this process is tightly regulated by intrinsic molecules, e.g. transforming growth factor family proteins [31, 32] and by extrinsic factors, e.g. aging, stress and physical activity [26, 33, 34], added a new dimension in the possibilities of regulation and modulation of cognition.

Concerning LTCCs as potential modulators of adult neurogenesis and cognition, convincing evidence from in vitro studies [35-38] and from work on rodent brain slices [39] has demonstrated that immature NSC and NPC carry functional LTCCs.Electrophysiological analyses have confirmed LTCC-induced $\mathrm{Ca}^{2+}$ currents in subventricular zone derived NSCs and NPCs from embryonic rats [37], in NPCs from postnatal mice [36], and in adult hippocampal NPCs [35]. Consistently, $\mathrm{Ca}^{2+}$ influx through LTCCs controls the neuronal differentiation of NSCs and NPCs into mature neurons [35, 36, 38]. Excitation of LTCCs induced premature differentiation of proliferating NPCs, while treatment with nifedipine, a dihydropyridine calcium channel blocker primarily blocking LTCCs [40] inhibited neuronal differentiation[36]. Based on these findings, Deisseroth and colleaguesfurther examined possible effects of LTCCs on NSC and NPC behavior and on adult neurogenesis in vivo[35]. Indeed, a 1-week treatment of adult rats withnifedipinesignificantly reduced the fraction of newborn neurons in the hippocampal dentate gyrus, and administration of the LTCC activator BayK 8644 elevated the numbers of newborn dentate gyrus granular neurons[35].Hence, these findings clearly demonstrated that hippocampal neurogenesis is regulated by Cav1.2/Cav1.3 channel activity in the adult brain. However, it is unclear which cell types in the dentate gyrus are targeted by LTCC modulation (e.g. NSCs, NPCs, mature neurons), and which steps in adult neurogenesis (proliferation, cell survival, cell differentiation and fate determination) are affected. Further, the impact of aging on LTCC expression and 
functionalityis still controversially discussed, with some authors reporting increased [41]and others reduced [42, 43] LTCC expression levels in the hippocampus of aged animals. To what extent the presumed changes in LTCC properties in the aged hippocampus might contribute to the reduced levels of neurogenesis in aged individuals, has not been addressed so far.Additionally, possible consequences of LTCC-induced changes in hippocampal neurogenesis on learning and memory remain to be addressed.

Here we analyze the expression patterns of the LTCC isoforms Cav1.2 and Cav1.3 in the main neurogenic niches,the dentate gyrus of the hippocampus and the subventricular zone, of adult (2-3-month)and middle-aged (15-month)mice. Using homozygous Cav1.3 knockout mice, we also examine the relevance of Cav1.3 for hippocampal neurogenesis in adult and middle-aged mice, and address the importance of Cav1.3 in adult mice for hippocampal function by evaluating depressive-like behavior and spatial memory in Cav1.3.- mice. 


\section{Materials \& methods}

\subsection{Animals}

Experiments were carried out in accordance with the European Community Council Directive (86/609/EEC) and were approved by the local animal health commission. For the in vivo experiments, adult (3months) and middle-aged (15 months) female homozygous Cav1.3 knockout mice were used [44]. Cav1.3-- mice were backcrossed for at least five generations into a C57BL/6N background. Wildtype (WT) C57BL/6N mice were used as control animals. qRT-PCR analysis of Cav1.2 and Cav1.3 mRNA, and immunohistological examination of Cav1.2 protein expression were performed with brain tissue from 3-month and 15-month old female C57BL/6 wildtype mice. All animals were housed under standard conditions of a 12 hour light/dark cycle with food and water ad libitum. Mice were group-housed and genders were kept separated.

For immunohistological analysis of Cav1.3 (Cacna1d), due to the lack of reliable antibodies, 2-monthand 15-month old heterozygous mice of the Ella::Cre;Cacna1d-eGFP ${ }^{\text {flex }}$ reporter line [45] were provided by DusanBartsch, Central Institute of Mental Health, Mannheim, Germany. In this model, ablation of Cav1.3 is coupled to the expression of the reporter gene eGFP under the control of the Cacna1d promoter.

\subsection{BrdU injections}

For the histological analysis of cell survival and cell fate, mice received intraperitoneal injections of $10 \mathrm{mg} / \mathrm{ml}$ of the thymidine analogue $\mathrm{BrdU}$ (Sigma) at $50 \mathrm{mg} \mathrm{kg}^{-1}$ of body weight dissolved in $0.9 \% \mathrm{NaCl}$ solution daily on five consecutive days four weeks before perfusion.

\subsection{Perfusion and tissue processing}

Mice were deeply anaesthetized using a ketamine $(20.38 \mathrm{mg} / \mathrm{ml})$, xylazine $(5.38 \mathrm{mg} / \mathrm{ml})$ and acepromazine $(0.29 \mathrm{mg} / \mathrm{ml})$ mixture. Transcardial perfusion was performed with $0.9 \%$ 
NaClsolution, followed by a $4 \%$ paraformaldehyde, $0.1 \mathrm{M}$ sodium phosphate solution $(\mathrm{pH}$ 7.4). The brains were dissected and post-fixed in the paraformaldehyde solution overnight at $4^{\circ} \mathrm{C}$. Tissues were then cryoprotected in a $30 \%$ sucrose, $0.1 \mathrm{M}$ sodium phosphate solution (pH 7.4). Brains were cut into $40 \mu \mathrm{m}$ saggital sections using a sliding microtome on dry ice. Sections were stored at $-20^{\circ} \mathrm{C}$ in cryoprotectant solution (ethylene glycol, glycerol, $0.1 \mathrm{M}$ phosphate buffer $\mathrm{pH} 7.4,1: 1: 2$ by volume).

\subsection{Immunohistochemistry}

Immunohistochemistry was performed as previously described[32]. The following antibodies and final dilutions were used. Primary antibodies: rabbit anti-Cav1.2 (1:500, Sigma Aldrich), rat anti-BrdU (1:500, Serotec), mouse anti-Nestin (1:300, Abcam), goat anti-Doublecortin (1:200, Santa Cruz), rabbit-anti Doublecortin (1:300, Cell Signaling), guinea pig anti-GFAP (1:500, Progen), mouse anti-NeuN (1:500, Millipore), goat anti-PCNA (1:250, Santa Cruz), chicken anti-GFP (1:500, Invitrogen). Secondary antibodies: donkey anti-goat, -rabbit, chicken Alexa 488, donkey anti-guinea pig Alexa 568, donkey anti-goat, -guinea pig, -mouse Alexa 647 (all 1:1000, Invitrogen), donkey anti-mouse, -goat, -rat biotinylated (all 1:500, Jackson Immuno Research). Nuclear counterstaining was performed with 4', 6'-diamidino-2phenylindoledihydrochloride hydrate at $0.25 \mu \mathrm{g} / \mu \mathrm{l}$ (DAPI; Sigma). Chromogenic immunodetection was photodocumented using a Zeiss Axioplan microscope (Zeiss, Germany) equipped with the ZeissAxioVision imaging system. Epifluorescence observation was performed on a confocal scanning laser microscope (LSM 700, Zeiss) with LSM software (ZEN 2011).

\subsection{Quantitative analysis of immunohistological data}

All qualitative and quantitative analysisof the dentate gyruswere performed in the dorsal hippocampus. For quantification of different cell types, analyses were performed blinded on coded slides. Every $10^{\text {th }}$ section $(400 \mu \mathrm{m}$ interval) of one brain hemisphere was selected from each animal and processed for immunohistochemistry. 
Numbers of PCNA-, BrdU-, Nestin- and DCX- labeled cells within the dentate gyrus were determined on every tenth section and multiplied by the interval.The volume of the granule cell layer of the dentate gyrus (DG) was determined by tracing the dentate gyrus of each examined section using a Zeiss Axioplan microscope (Zeiss, Germany) and multiplying the measured area with the section thickness and interval.

Analysis of cell differentiation was investigated by detection of NeuN and GFAP staining in BrdU-labeled cells using the LSM 710 confocal scanning laser microscope. 50 BrdU-labeled cells were analysed for each marker. Due to the lower level of neurogenesis in old animals, in case the total number of BrdU-positive cells remained below 50 in the 15-month old mice, every BrdU-labeled cell detected was examined.

To analyse density of GFAP immunostaining in the hippocampus, the surface labeled with anti-GFAP was estimated. Per animal, four visual fields of the dorsal part of the dentate gyrus (one image each from four randomly selected $\mathrm{GFAP}^{+}$stained saggital brain sections; GFAP staining was performed on every $10^{\text {th }}$ brain section of one brain hemisphere)were photographed with a 20x objective and a resolution of $1024 \times 1024$ pixels using a confocal scanning laser microscope (LSM 700, Zeiss) with LSM software (ZEN 2011). Images were converted to grey scale (Adobe Photoshop CS2, Adobe) prior to the selection of a detection threshold. The percentage of pixels containing labeling was quantified for every picture usinglmageJ $1.45 \mathrm{~s}$ (ImageJ website: http://imagej.nih.gov/ij/).

\subsection{Object location memory test}

Object location was performed as previously described [46]. Prior to training, mice were handled 1-2 $\min$ for 3 days and then habituated to the experimental apparatus for $5 \mathrm{~min} \mathrm{~d}^{-1}$ for 3 days in the absence of objects. During the training period, mice were placed into the experimental apparatus with two identical objects (Lego square blocks made of plastic and blue in color) and allowed to explore for $15 \mathrm{~min}$. During the long-term retention test, i.e., $24 \mathrm{~h}$ 
following the training period, one of the object location was shifted and the mice were allowed to explore the experimental apparatus for $10 \mathrm{~min}$. Exploration was scored when a mouse's head was oriented toward the object within a distance of $1 \mathrm{~cm}$ or when the nose was touching the object. The relative exploration time $(t)$ was recorded and expressed as a discrimination index $\left(D I=\left(t_{\text {novel }}-t_{\text {familiar }}\right) /\left(t_{\text {novel }}+t_{\text {familiar }}\right) \times 100 \%\right)$. Mean exploration times were then calculated and the discrimination indexes between treatment groups compared. Mice that explored both objects for less than $3 \mathrm{~s}$ in total during either training or testing were removed from further analysis.

\subsection{Sucrose preference test}

The sucrose preference test was conducted based on the modification of a previously published study[47]. During this test, mice were given a free choice between two bottles, one with an escalating dose of $0.5 \%-1 \%$ sucrose and another with tap water. The position of the bottles were switched every $24 \mathrm{~h}$ to prevent the possible effects of side preference in drinking behavior. No food or water deprivation was applied before or during the test. The consumption of water and sucrose solution was determined simultaneously in control and experimental groups by weighing the bottles. Each session (S) denotes an average of sucrose preference with the bottle each time on the left and the right side. The preference for sucrose was calculated as a percentage of consumed sucrose solution to the total amount of liquid consumed.

\subsection{RNA extraction from mouse brain tissue and quantitative real time-PCR analysis}

To detect mRNA levels of Cav1.2 and Cav1.3 in different brain regions of 3-month and 15month old WT mice, total RNA was extracted from mouse hippocampus, subventricular zone and cortex. Animals were decapitated and the tissues of interest were dissected. Brain samples were homogenized in $1 \mathrm{ml}$ Trizol/ $100 \mathrm{mg}$ tissue (TRI® Reagent; Sigma). For phase separation, $200 \mu \mathrm{l}$ of 1-bromo-3-chloropropane were added, vortexed and centrifuged (15 min at $12000 \mathrm{~g}$ ). After transferring the aqueous phase into a new tube and adding $350 \mu \mathrm{l}$ of 
ethanol, RNA extraction was performed using the QIAGEN RNEasy Mini Kit (Qiagen) and cDNA was synthesized using the iScript Reverse Transcription Supermix (Biorad).

Quantitative gene expression analyses were performed using TaqMan RT-PCR technology. Technical duplicates containing $10 \mathrm{ng}$ of reverse transcribed RNA were amplified with the GoTAQ Probe qPCR Master Mix (Promega) using a two-step cycling protocol $\left(95^{\circ} \mathrm{C}\right.$ for $15 \mathrm{~s}$, $60^{\circ} \mathrm{C}$ for $60 \mathrm{~s} ; 40$ cycles, Bio-Rad CFX 96 Cycler). The following validated exonspanninggene expression assays were employed: Cav1.2 (Mm00437953_m1, Applied Biosystems) and Cav1.3 (Mm01188_m1, Applied Biosystems).From a set of 6 validated candidate housekeepers, the two best fitting were chosen for the present experiments (PSMD4, Mm.PT.56.13046188; Heatr3 Mm.PT.56.8463165; both Integrated DNA Technologies). Quantification analyses were performed with qBasePlus (Biogazelle) using geNorm algorithms for multi-reference gene normalization, followed by normalization to control conditions. Bars represent 3 mice each $(n=3)$ for every group or brain region.

\subsection{Statistical analysis}

Statistical analyses were performed using the GraphPad Prism 5.0 software (GraphPad Software). Data were tested for normality using the Kolmogorov-Smirnov or the ShapiroWilktest. Means between two groups were compared by the two-tailed unpaired Student's ttest. Data from multiple groups were analysed by one-way analysis of variance (ANOVA), and two-way ANOVA, followed by Bonferroni post hoc tests when necessary. P values of $p<$ $\left.0.001{ }^{(* *}\right)$ were considered most significant, $p<0.01\left(^{* *}\right)$ highly significant, and $p<0.05\left(^{*}\right)$ significant. All values were expressed as means \pm standard deviation (SD), unless otherwise stated. 


\section{Results}

\subsection{The LTCC isoforms Cav1.2 and Cav1.3 are expressed within the adult neurogenic regions}

The presence of Cav1.2 and Cav1.3 has been demonstrated in several brain regions on the mRNA and protein levels (e.g. [4, 6]). Here we confirmed and extended the present knowledge on LTCC brain expression by performing qRT-PCR of Cav1.2 and Cav1.3 mRNA in non-neurogenic (cortex) and neurogenic (hippocampus, subventricular zone (SVZ)) regions ofadult (3-month) and middle-aged (15-month) mice. Further, we specified Cav1.2 and Cav1.3 distribution within the neurogenic regions by immunohistological (IHC) colabeling of the respective receptor subtype with cell-type specific markers in the dentate gyrus (DG) of the hippocampus and in the SVZ.

Cav1.2 mRNA was detected in the hippocampus, SVZ and cortex of 3-month and 15-month old wildtype (WT) mice (Fig. 1a). In both age-groups, the hippocampus and thecortex (a region for which abundant Cav1.2 mRNA expression is well-documented [4, 5]), showed similar expression levels. In the SVZ, Cav1.2 mRNA levels weresignificantly lower compared to the $\mathrm{HC}$ in the middle-aged mice, while in the 3-monthold mice no differences were observed. Between age groups, however, no significant differences in Cav1.2 expression levels were detected(Fig. 1a). IHC analysis of the hippocampal DG and the SVZ of adult and middle-aged mice confirmed Cav1.2 expression in these neurogenic regions on the protein level.Intensity and pattern of Cav1.2 immunostaining were similar between age-groups(Fig. $1 b, c)$. In detail, in the DG of 3-month old mice intense Cav1.2 staining was localized to the cell somata and dendrites of $\mathrm{NeuN}^{+}$granular neurons (Fig. 1f), and several GFAP ${ }^{+}$cells of mature astrocyte morphology were positive for Cav1.2 at this site (Fig. 1g). In contrast, Cav1.2 immunoreactivity was not detected in Nestin ${ }^{+}$NSCs and was only rarely observed in $\mathrm{DCX}^{+}$immature neurons (Fig. 1d,e).In the SVZ, Cav1.2 antibody staining pattern was similar to the distribution observed in the DG. A high amount of $\mathrm{NeuN}^{+}$mature neurons within the 
parenchyma next to the SVZ showed intense Cav1.2 labeling, and some Cav1.2 ${ }^{+} / \mathrm{GFAP}^{+}$ astrocytes were detected within the SVZ. Again, Nestin ${ }^{+}$NSCs did not express Cav1.2, and only a few Cav1.2 $/ \mathrm{DCX}^{+}$co-labeled neuronal progenitor cells were detected (Fig. 1h-k).In the 15-month old animals, the cell-type specific expression pattern of Cav1.2 was similar to the one of 3-months old mice (data not shown).

Concerning the LTCC isoform Cav1.3, mRNA was detected at similar expression levels in the hippocampus, cortex, and SVZ in both age groups. Further, no differences in Cav1.3 mRNA expression levels between 3-month and 15-month old mice were observed(Fig. 2a). Due to the lack of reliable antibodies for Cav1.3, we used the Ella::Cre x Cacna1d-eGFP flex reporter line for IHC analysis of Cav1.3 expression in the DG and SVZ. As previously demonstrated, GFP expression in heterozygous recombined animals reflects Cav1.3 expression, and the heterozygous loss of Cav1.3 does not influence neuronal function [45]. In adultand middleagedmice, the GFP signal was detected in both neurogenic regions. No obvious age-related differences in the GFP expression pattern and intensity were observed in the SVZ. In contrast, in the dentate gyrus, in particular within the granular layer, GFP expression was more intense in the middle-aged compared to the adult animals (Fig. 2b,c). The more detailed analysis of the GFP expression within the neurogenic niches of adult mice revealed thata GFP signal of medium intensity was observed in $\mathrm{NeuN}^{+}$mature neurons within the granular layer of the DG. For NSCs, moderate GFP expression was found in several Nestin ${ }^{+}$cells as well as on some $\mathrm{GFAP}^{+}$cells of radial glia-like morphology. The majority of $\mathrm{DCX}^{+}$neuronal progenitors was absent of GFP signal, however a few $\mathrm{GFP}^{+} / \mathrm{DCX}^{+}$cells exhibiting a more immature phenotype could be detected within the subgranular layer. Additionally, several $\mathrm{GFP}^{+} / \mathrm{GFAP}^{+}$cells of stellate astrocyte morphology were detected (Fig. $2 \mathrm{~d}-\mathrm{g}$ ).In the SVZ, the $\mathrm{GFP}^{+}$signal was most abundant within the ependymal cell layer. Further, similar to the expression pattern in the DG, GFP co-localized with several Nestin ${ }^{+} \mathrm{NSCs}$, with some GFAP ${ }^{+}$ cells of NSC like (radial) morphology, and with a few $\mathrm{GFAP}^{+}$cells of stellate astrocyte morphology. In $\mathrm{DCX}^{+}$neuronal progenitors of the SVZ, GFP signal was never detected (Fig. 
2 h-k).In the 15-month old animals, although intensity of GFP signal was higher in middleaged mice, the cell-type specific expression pattern of GFP in the Ella::Cre $x$ Cacna1deGFP flex was similar to the one of 3-months old animals (data not shown).

Together, PCR and IHC analysis demonstrate that both Cav1.2 and Cav1.3 are expressed within the murine adult neurogenic niches. While Cav1.2 is primarily restricted to $\mathrm{NeuN}^{+}$ granular neurons, Cav1.3 is additionally expressed by Nestin ${ }^{+}$SSCs. Hence, the biphasic expression pattern of Cav1.3, first in NSCs and later in mature neurons suggests a particular role of this LTCC isoform in hippocampal neurogenesis.

\subsection{Decreased rates of adult hippocampal neurogenesis in Cav1.3 ${ }^{-/-}$mice}

We next examined if ablation of Cav1.3 in Cav1.3 $3^{-/-}$mice had effects on DG neurogenesis in adult and middle-aged animals (Fig. 3). First, the DG volume (subgranular and granular zone) of 3-month old Cav1.3 $3^{-/-}$mice was significantly reduced compared to WT animals. In middle-aged mice, this effect was even more pronounced (Fig. 3a). Evaluation of cell proliferation by quantitative analysis of $\mathrm{PCNA}^{+}$cells in the DG revealed no differences in the 3-month age group, but showed a significant reduction in the proliferation rate in 15-month old Cav1.3 $3^{-/-}$mice compared to WT (Fig. 3b). As this could be due to a reduced number of NSCs present in the niche, we determined the numbers of Nestin $^{+}$cells in the DG. Interestingly, a significant lower number of Nestin ${ }^{+}$NSCs was observed in 3-month old Cav1.3 $3^{-/-}$mice (Fig. 3c) compared to WT. Within the 15-month age group, Cav1.3 $3^{-/}$mice showed a tendency for reduced Nestin $^{+}$cell numbers, however, this did not reach significance. The pool of $\mathrm{DCX}^{+}$immature neurons was not affected by the genotype in both age groups (Fig. 3d). We next analyzed if the survival and differentiation fate of newborn cells was changed in Cav1.3 $3^{--}$mice. Both 3- and 15-month old knockout mice showed a strong decrease of BrdU positive cell numbers (i.e. cells that had incorporated BrdU 4 weeks before) in the DG, indicating an impaired survival of newly generated cells in the absence of 
Cav1.3 (Fig. 3e). Addressing the fate of the newly generated cells in the DG, we assessed the percentages of $\mathrm{BrdU}^{+}$cells co-labeling with $\mathrm{NeuN}$ for mature neurons or with GFAP for astrocytes (Fig. 3f). The fraction of $\mathrm{BrdU}^{+} / \mathrm{NeuN}^{+}$cells was clearly reduced in 3-month old Cav1.3/- mice compared to age-matched WT $(65.57 \pm 7.04 \%$ in WT; $46.19 \pm 12.88 \%$ in Cav1.3 $\left.{ }^{\prime}\right)$. The percentages of $\mathrm{BrdU}^{+} / \mathrm{GFAP}^{+}$cells were similar in the younger age group (27.49 $\pm 10.13 \%$ in WT; $31.97 \pm 1.3 \%$ in $\mathrm{Cav}_{1.3^{-/}}$), but the portion of BrdU cells neither expressing NeuN nor GFAP $\left(\mathrm{BrdU}^{+} / \mathrm{NeuN}^{-} / \mathrm{GFAP}^{-}\right)$was tripled in the Cav1.3 ${ }^{-/-}$mice $(6.95 \pm 3.12 \%$ in WT; $21.83 \pm 12.17 \%$ in Cav1.3 $3^{--}$). The shift of cell differentiation in the 3-month age group resulted in a highly significant reduction in the number of newly generated neurons $\left(\mathrm{BrdU}^{+} / \mathrm{NeuN}^{+}\right)$in Cav1.3 $3^{-/-}$mice compared to WT (Fig. 3g). In middle-aged mice, the percentages of $\mathrm{BrdU}^{+}$colabeled cells were similar between genotypes (WT: $55.56 \pm 9.62 \%$ NeuN, $37.41 \pm 3.57 \%$ GFAP, $7.04 \pm 6.12 \%$ others; Cav1.3 ${ }^{-/}: 47.62 \pm 4.12 \%$ NeuN, $38.73 \pm 4.89 \%$ GFAP, $13.65 \pm 3.38 \%$ others).

In addition to neurogenesis, we evaluated possible effects of Cav1.3 deletion on astroglia. Even though cell fate analysis demonstrated no impact of the genotype on the numbers of newly generated $\mathrm{GFAP}^{+}$astrocytes (Fig. $3 f, g$ ), a strong reduction in the GFAP staining intensity was apparent. On a closer analysis, the GFAP surface area in the DG of 3-month old Cav1.3 $3^{-/-}$mice was severely reduced, in particular within the granular/subgranular layer (Fig. 3i). In 15-month old mice, this altered GFAP ${ }^{+}$phenotype was no longer observed (Fig. 3j).

Next, we raised the question whether the alterations in neurogenesis in Cav1. $3^{-/-}$mice are of cell-autonomous nature and would be maintained in vitro when NPCs were taken out of their niche. Therefore, we prepared NPC cultures from hippocampi of 3-month old Cav1.3/- and WT mice and evaluated neurogenesis in vitro.Numbers and volumes of neurospheres from freshly isolated NPCs (passage 0) were similar for Cav1.3 $3^{--}$and WT derived NPCs (Supplementary Fig. 1a-c). Further, the lack of Cav1.3 did not affect NPC proliferation in a 
MTS assay (Supplementary Fig. 1d). To detect possible effects of Cav1.3 deletion on the cell identity and differentiation fate of NPCs in vitro, we immunocharacterized Cav1.3 and WT derived NPCs under differentiation conditions (growth factor withdrawal) by using markers for neurons (Map2ab) and astrocytes (GFAP). NPC cultures showed a very similar marker expression profile, indicating that Cav1.3 knockout did not change the differentiation fate of NPCs in vitro (Supplementary Fig. 1f). Further, the morphology of Map2ab ${ }^{+}$neurons and $\mathrm{GFAP}^{+}$astrocytes derived from Cav1.3 $3^{-/-}$NPCs was not different compared to differentiated NPCs derived from WT mice (Supplementary Fig.1e). In summary, although Cav1.3 deletion leads to a clear decrease of hippocampal neurogenesis in adult and middle-aged mice, these effects were not reflected by NPC behaviorin vitro. Hence, additional external stimuli present in the niche may be required for the in vivo effects of Cav1.3 knockout on adult neurogenesis and on astroglia to become apparent.

\subsection{Impaired cognition in the object location memory taskin Cav1.3 $3^{-/}$mice}

As Cav1.3 deletion provoked a decrease of hippocampal neurogenesis in adult mice, we next asked if lack of Cav1.3 has consequences on hippocampal functions, in particular on cognition and on depression-like behavior.We conducted the sucrose preference test, to evaluate anhedonia which is a recognised feature of human depression [47]. The animal's preference in drinking sweet sucrose containing water compared to plain drinking water was measured over a five week-period with increasing sucrose concentrations $(0.5 \%, 0.6 \%$, $0.75 \%$ and $1 \%$ ). Typically, in both 3 month-old Cav1.3.- and WT the preference toward the sucrose-containing water increased with increasing sucrose levels, however, there were no differences between both groups in terms of sucrose preference (Fig. 4a) indicating no differences in anhedonia-like behavior in both the genotypes.

Next, to examine hippocampus-dependent memory function in 3-month old Cav1.3 ${ }^{-/}$mice, we performed the object location memory test [46]. This test is based on the spontaneous 
tendency of rodents to spend more time exploring a novel object than a familiar object and to recognize when an object has been relocated. Remarkably, the Cav1.3/- mice exhibited a significantly impaired object location discrimination index compared to WT mice (Fig. 4b). These data indicate strongly impaired spatial memory function in adult Cav1.3 $3^{-/-}$mice. 


\section{Discussion}

We examined the expression of LTCCs within the adult neurogenic regions, i.e. the hippocampal dentate gyrus and the SVZ, and found Cav1.2 and Cav1.3 immunoreactivecell populations at different and specific stages of neuronal differentiation. We addressed the significance of Cav1.3 for dentate gyrus neurogenesis using adult (3-month) and middleaged (15 month)Cav1.3 ${ }^{-/}$mice, and we observed a crucial role of this LTCC isoform in proper neurogenesis functions. Further, we detected impaired performance of Cav1. $3^{-/-}$mice in the dentate gyrus dependent object location memory test, implicating Cav1.3 as an essential element for hippocampus-associated cognitive functions.

Previous studies have described the presence of Cav1.2 and Cav1.3 within the adult hippocampus on mRNA and protein levels [4, 12, 48]. Here, we add detailed immunohistological information on the expression of Cav1.2 and Cav1.3 in non-differentiated neural stem- and progenitor cells within the adult hippocampal dentate gyrus. Cav1.2 expression was restricted to cells at the final stages of neuronal differentiation, whereas Cav1.3 (indicated by presence of EGFP in adult Cacna1d-eGFP flex +/- mice) displayed a biphasic expression pattern during neurogenesis: beyond expression in mature granular neurons, Cav1.3::EGFP was additionally present in the NSC population. The Cav1.2 expression pattern found in the present work is in agreement with earlier in vitro and in situ studies, which demonstrated a progressive increase of LTCC expression and activity along neuronal differentiation [35-39].In contrast, a biphasic expression pattern of LTCCs, as we observed it for Cav1.3 has not been described before. This may be partly because most of the previous studies did not analyze Cav1.2 and Cav1.3 separately, a limitation that could mask distinct expression dynamics of these LTCC isoforms. The existence of LTCCs specifically in NSCs, though, has been described for fetal rat NSCs [49], and recently, Teh and colleagues detected moderate expression of Cav1.3 but only weak expression of Cav1.2in the adult hippcampus derived PZ5 NSC line[38]. 
LTCCs on cell populations at the final stages of neurogenesis have been shown to regulate the survival of neuronal progenitors and the functional maturation of neurons $[35,36,38]$. The role of LTCCs, especially of Cav1.3, in the NSC population has not been addressed so far. Recently, a functional coupling of Cav1.3 and GABAB receptors has been reported, showing that activation of GABABR increased Cav1.3, but not Cav1.2-mediated $\mathrm{Ca}^{2+}$ currents in cultured hippocampal neurons [50]. Since GABA receptors are involved in maintenance and activation of hippocampal NSCs[51, 52], GABA receptors and Cav1.3 may be part of the same signaling pathway for stem cell maintenance. A similar dual role during adult neurogenesis has already been suggested for TGF- $\beta 1[32]$. We have recently demonstrated that treatment of adult neuronal progenitor cells with TGF- $\beta 1$ increased LTCC activity in these cells[53]. Moreover,TGF- $\beta 1$ elevated Cav1.3 mRNA expression in cerebellar granular neurons in vitro [54].

Concerning potential changes of hippocampal LTCC expression along aging, we did not observe differences on mRNA levels between adult and middle-aged mice. On protein level, qualtitative analyses revealed slight differences in hippocampal Cav1.3 expression pattern between age-groups, in that Cav1.3 expression intensity was higher in the dentate gyrus granular layer in middle-aged than in adult animals. Existing data on age-related changes of LTCC expression are conflicting, ranging from increased LTCC expression in the aged brain [41] to no changes [55]or decreased expression[42, 43]. This discrepancy may be partly due to different methods of analysis, since Nunez-Santana and colleagues have recently shown that Cav1.2 and Cav1.3 expression in the hippocampus of 32 months old rat is reduced on the protein, but not on the mRNA level[56]. Further, different age-groupsand strains examined in these studies (from 12-month old mice to 32-month old rats)might contribute to the incoherent picture. It might likely be that the 15-month old mice analyzed in the present work were too young to find alterations in hippocampal LTCC expression, and that these mice would develop differences in LTCC properties in later life. 
Besides the expression pattern of Cav1.2 and Cav1.3in the neurogenic regions, the present study was aimed to define the role of Cav1.3 in adult hippocampal neurogenesis by using Cav1.3 $3^{-/}$mice. Since the protein expression of Cav1.3 in the hippocampus was slightly changed between young and middle-aged animals, we analyzed neurogenesis in both age groups, as age-related molecular changes in the hippocampus might well influence LTCC signaling. In adult and middle-aged Cav1. $13^{-/}$mice, the survival of newly generated cells in the DG was severely impaired compared to age-matched WT. Further, the percentage of newly generated cells entering the neuronal lineage was clearly lower in 3 month-old Cav1.3I- mice (46\%) compared to WT (65\%), which actually resulted in a more than 2 -fold reduction of newly generated neurons in the DG of the Cav1.3/- mice. These detrimental effects of Cav1.3 knockout on survival and neuronal differentiation of newly generated cells within the DG corroborate the in vitro findings of LTCC involvement in the later stages of neurogenesis [36, 38], and are in agreement with in vivo data from Deisseroth et al. [35]. Interestingly, the reduced rate of neuronal differentiation in our study was obviously not due to a fate shift towards the astroglial lineage, since the fraction of newly generated astrocytes was unchanged between Cav1.3/- and WT mice. Yet, we observed a clear increase in $\mathrm{BrdU}^{+}$cells that were neither positive for NeuN nor for GFAP. Teh et al. also found no effects on astroglial differentiation when treating the PZ5 adult rat hippocampal NSC line with LTCC activators and antagonists; however, they detected a significant reduction of the oligodendrocytic fraction after LTCC activator administration[38]. In view of these findings, the increase of $\mathrm{BrdU}^{+}$cells in Cav1.3 $3^{-/-}$mice could refer to an increase of oligodendrocytes. Thus, LTCCs, while fostering differentiation into neurons, may inhibit the differentiation into oligodendrocytes.

Cav1.3 knockout had no effects on proliferation and on the numbers of $\mathrm{DCX}^{+}$immature neurons in 3-month old Cav1.3 ${ }^{-/-}$mice, suggesting that Cav1.3 does not affect the expansion phase of neurogenesis. This is again in agreement with Teh et al. [38], who found no effects of LTCC activation and inhibition on the proliferation of PZ5 cells. Yet, we observed a 
reduction of the Nestin NSC pool in the 3-month old Cav1.3 ${ }^{-/-}$mice compared to WT. This finding supports the hypothesis that Cav1.3 may play a role in stem cell maintenance (see above). In contrast in middle-aged mice, we observed a clear reduction in cell proliferation, while NSC numbers were not affected. This may be explained by the altered neurogenic environment within the aged neurogenic niche, which leads to several changes of mitogenic and anti-mitotic factors that in the following contribute to decreased neurogenesis in the aged brain $[57,58]$. The interplay of such microenvironmental and systemic factors within the aged brain may compensate and/or override LTCC-induced effects on neurogenesis, which of course requires further experimental evidence.

We also observed a severe reduction of GFAP $^{+}$immunoreactive area in the DG of 3-month old Cav1.3 $3^{-/}$mice. Morphological analysis of $\mathrm{GFAP}^{+}$astrocytes in the $\mathrm{DG}$, together with the finding that the numbers of newly generated astrocytes were unchanged, point toward ahypotrophicastrocyte phenotype, and let also suggest altered gene expression inCav1.3/astrocytes. A subset of astrocytes in the hippocampus indeed expresses Cav1.3 (Fig. 2g) $[46,59]$, and upregulation of Cav1.3 has been demonstrated in reactive astrocytes of the mouse hippocampus after pilocarpine-induced status epilepticus[60]. Thus, Cav1.3 may contribute to volume regulation and modulation of the activity state of astrocytes in the hippocampus and could be involved in astrogliosis in chronic neurodegenerative disorders such as Alzheimer's disease or in acute CNS lesions such as spinal cord injury.

The observed effects of Cav1.3 knockout on neurogenesis in vivo were not reflected in vitro. Compared to wildtype NPCs, hippocampal NPCs from adult Cav1.3 $3^{-/-}$mice showed neither alterations in proliferation and cell differentiation, nor in astrocyte morphology. Thus, electrical or chemical stimulation from the neurogenic environment in vivo may be essential for the LTCC-mediated effects on neurogenesis and emphasizes the need for in vivo analysis. 
Due to the detrimental effects of Cav1.3 knockout on hippocampal neurogenesis, we were interested whether Cav1.3 $3^{-/}$mice showed alterations in hippocampal functions that are commonly related to adult neurogenesis. Adult neurogenesis is often impaired in animal models of depression [61], and anti-depressant treatments have been reported to increase neurogenesis levels $[62,63]$. Here, we evaluated depressive-like behavior in 3-month old Cav1.3 ${ }^{-/}$mice using the sucrose preference test, a non-stressful behavioral task to measure anhedonia[47]. We did not find any differences in sucrose preference between Cav1.3 ${ }^{-/}$and WT, implicating that reduced neurogenesis and Cav1.3 knockout does not provoke anhedonia in this model. However, we have observed previously that Cav1.3 ${ }^{-/}$mice show decreased depression-like behavior[18]. The present data therefore suggest that depressionassociated anhedonia and the changes mediated in the forced-swim test or tail-suspension test, behaviors that are used to predict antidepressant efficacy, may require different synaptic and circuit modifications [15, 64], and, moreover, are not dependent on dentate gyrus neurogenesis.

In addition to depression-like behavior, we assessed memory performance in 3-month old Cav1. $3^{-/}$mice, since it is well established that hippocampal neurogenesis is involved in specific functions in learning and memory, in particular in spatial cognition and pattern separation [29, 30, 65-67]. We conducted the object location memory task, a test specifically involving the hippocampus [46], and observed an impaired object location memory in the transgenic mice compared to WT. This finding shows that Cav1.3 is essential for memory functions, and strongly suggests that reduced neurogenesis in adult Cav1.3 $3^{-/}$mice is involved in these memory impairments.

Obviously, since a general Cav1.3 knockout model was analyzed, the reduced levels of neurogenesis and impaired cognitive functions observed in theCav1.3 ${ }^{-/-}$mice can not be directly related to the deletion of Cav1.3 in cells within the dentate gyrus, The observed changes could also be due to Cav1.3 $3^{-/}$associated phenotypes and compensatory effects. 
These mice are congenitally deaf, and they show resting bradycardia and arrhythmia, which disappear during physical activity [44]. However, apart from that, Cav1.3 knockout does not compromise motor functions, spontaneous activity, food/water intake or acute pain, and on a molecular level, does not lead to compensatory up-regulation of Cav1.2 mRNA and protein in the brain $[2,68]$. The observed impairments in neurogenesis and memory functions in Cav1.3/- mice could also be partly mediated by Cav1.3 deletion in cells in other brain regions than in the hippocampus.In this context, Cav1.3 channels in dopaminergic neurons are known to be causally involved in dopamine release [69, 70], and a crucial role of dopamine and its D2-receptors is well documented[71-74]. Thus, the observed effects of Cav1.3 knockout could likely, at least in part, be mediated by a loss of Cav1.3 in dopaminergic midbrain neurons and a respective altered amount of dopamine and D2-receptorstimulation within the neurogenic regions.Despite of this, the Cav1.3.expression pattern in combination with the effects on neurogenesis and cognition provide a coherent picture of the role of Cav1.3 in adult neurogenesis and -associated functions. Future analysis, however, will need to address the consequences of inducible and neurogenesis specific Cav1.3 deletions on NSC activity and behavior.

The present data extend the information on the complex involvement of LTCCs in hippocampus-dependent learning and memory. In previous studies, knockout of Cav1.3 did not show alterations in LTP or spatial learning and memory $[16,68]$, however, it should be noted, that in these studies learning and memory was detected in morris water maze tasks which do not specifically address dentate-gyrus dependent learning. Here, by using the object location memory test, we may obtain more sensitive and specific results on cognitive skills related to the dentate gyrus and to neurogenesis.

\section{Conclusion}

To date, LTCC antagonists are suggested as therapeutics to ameliorate cognitive deficits in Alzheimer's disease $(A D)$, since in $A D$ increased activity and expression of LTCCs has been 
reported[75], and Cav1.3 blockers are currently developed to ameliorate motor symptoms in Parkinson's disease[76]. In the light of our results, showing detrimental effects of Cav1.3 deletion on neurogenesis and cognition, the long-term effects of LTCC blockersin the neurogenic niche should be considered for future therapeutic strategies. 


\section{Conflict of interest}

The authors declare that there is no conflict of interest.

\section{Acknowledgments}

This work was supported by the FWF Special Research Program (SFB) F44 "Cell Signaling in Chronic CNS Disorders". Moreover, this work has been made possible through the support from the State Government of Salzburg (Austria) (Stifungsprofessur, and 20204WISS/80/199-2014), the FWF Hertha-Firnberg Postdoctoral programme $\mathrm{n}^{\circ} \mathrm{T736-B24}$, the foundation Propter Homines (Liechtenstein), through funding from the European Union's Seventh Framework Program (FP7/2007-2013) under grant agreement n HEALTH-F2-2011278850 (INMiND) and n HEALTH-F2-2011-279288 (IDEA).

\section{References}

1. Sinnegger-Brauns MJ, Huber IG, Koschak A, Wild C, Obermair GJ, Einzinger U, Hoda JC, Sartori SB, Striessnig J. (2009) Expression and 1,4-dihydropyridine-binding properties of brain L-type calcium channel isoforms. Mol Pharmacol, 75, 407-14.

2. Striessnig J, Koschak A, Sinnegger-Brauns MJ, Hetzenauer A, Nguyen NK, Busquet P, Pelster G, Singewald N. (2006) Role of voltage-gated L-type Ca2+ channel isoforms for brain function. Biochem Soc Trans, 34, 903-9.

3. Striessnig J, Pinggera A, Kaur G, Bock G, Tuluc P. (2014) L-type Ca channels in heart and brain. Wiley Interdiscip Rev Membr Transp Signal, 3, 15-38.

4. Hell JW, Westenbroek RE, Warner C, Ahlijanian MK, Prystay W, Gilbert MM, Snutch TP, Catterall WA. (1993) Identification and differential subcellular localization of the neuronal class $C$ and class D L-type calcium channel alpha 1 subunits. J Cell Biol, 123, 949-62.

5. Lipscombe D, Helton TD, Xu W. (2004) L-type calcium channels: the low down. J Neurophysiol, 92, 2633-41.

6. Leitch B, Szostek A, Lin R, Shevtsova O. (2009) Subcellular distribution of L-type calcium channel subtypes in rat hippocampal neurons. Neuroscience, 164, 641-57.

7. Olson PA, Tkatch T, Hernandez-Lopez S, Ulrich S, Ilijic E, Mugnaini E, Zhang H, Bezprozvanny I, Surmeier DJ. (2005) G-protein-coupled receptor modulation of striatal CaV1.3 L-type Ca2+ channels is dependent on a Shank-binding domain. J Neurosci, 25, 1050-62.

8. Moosmang S, Haider N, Klugbauer N, Adelsberger H, Langwieser N, Muller J, Stiess M, Marais E, Schulla V, Lacinova L, Goebbels S, Nave KA, Storm DR, Hofmann F, Kleppisch T. (2005) Role of hippocampal Cav1.2 Ca2+ channels in NMDA receptor-independent synaptic plasticity and spatial memory. J Neurosci, 25, 9883-92. 
9. McKinney BC, Sze W, Lee B, Murphy GG. (2009) Impaired long-term potentiation and enhanced neuronal excitability in the amygdala of $\mathrm{Ca}(\mathrm{V}) 1.3$ knockout mice. Neurobiol Learn Mem, 92, 519-28.

10. Ma H, Cohen S, Li B, Tsien RW. (2013) Exploring the dominant role of Cav1 channels in signalling to the nucleus. Biosci Rep, 33, 97-101.

11. Deisseroth K, Mermelstein PG, Xia H, Tsien RW. (2003) Signaling from synapse to nucleus: the logic behind the mechanisms. Curr Opin Neurobiol, 13, 354-65.

12. Marshall J, Dolan BM, Garcia EP, Sathe S, Tang X, Mao Z, Blair LA. (2003) Calcium channel and NMDA receptor activities differentially regulate nuclear C/EBPbeta levels to control neuronal survival. Neuron, 39, 625-39.

13. Weick JP, Groth RD, Isaksen AL, Mermelstein PG. (2003) Interactions with PDZ proteins are required for L-type calcium channels to activate cAMP response element-binding proteindependent gene expression. J Neurosci, 23, 3446-56.

14. Grassi C, D'Ascenzo M, Azzena GB. (2004) Modulation of $\mathrm{Ca}(\mathrm{v}) 1$ and $\mathrm{Ca}(\mathrm{v}) 2.2$ channels induced by nitric oxide via cGMP-dependent protein kinase. Neurochem Int, 45, 885-93.

15. Lee AS, Ra S, Rajadhyaksha AM, Britt JK, De Jesus-Cortes H, Gonzales KL, Lee A, Moosmang S, Hofmann F, Pieper AA, Rajadhyaksha AM. (2012) Forebrain elimination of cacna1c mediates anxiety-like behavior in mice. Mol Psychiatry, 17, 1054-5.

16. McKinney BC, Murphy GG. (2006) The L-Type voltage-gated calcium channel Cav1.3 mediates consolidation, but not extinction, of contextually conditioned fear in mice. Learn Mem, 13, 584-9.

17. Busquet P, Hetzenauer A, Sinnegger-Brauns MJ, Striessnig J, Singewald N. (2008) Role of Ltype Ca2+ channel isoforms in the extinction of conditioned fear. Learn Mem, 15, 378-86.

18. Busquet $P$, Nguyen NK, Schmid E, Tanimoto N, Seeliger MW, Ben-Yosef T, Mizuno F, Akopian A, Striessnig J, Singewald N. (2010) CaV1.3 L-type Ca2+ channels modulate depression-like behaviour in mice independent of deaf phenotype. Int J Neuropsychopharmacol, 13, 499-513.

19. Levy A, Kong RM, Stillman MJ, Shukitt-Hale B, Kadar T, Rauch TM, Lieberman HR. (1991) Nimodipine improves spatial working memory and elevates hippocampal acetylcholine in young rats. Pharmacol Biochem Behav, 39, 781-6.

20. Quartermain D, deSoria VG, Kwan A. (2001) Calcium channel antagonists enhance retention of passive avoidance and maze learning in mice. Neurobiol Learn Mem, 75, 7790.

21. Woodside BL, Borroni AM, Hammonds MD, Teyler TJ. (2004) NMDA receptors and voltagedependent calcium channels mediate different aspects of acquisition and retention of a spatial memory task. Neurobiol Learn Mem, 81, 105-14.

22. Maurice T, Bayle J, Privat A. (1995) Learning impairment following acute administration of the calcium channel antagonist nimodipine in mice. Behav Pharmacol, 6, 167-175.

23. Oh MM, Oliveira FA, Disterhoft JF. (2010) Learning and aging related changes in intrinsic neuronal excitability. Front Aging Neurosci, 2, 2.

24. Gamelli AE, McKinney BC, White JA, Murphy GG. (2011) Deletion of the L-type calcium channel $\mathrm{Ca}(\mathrm{V}) \mathbf{1 . 3}$ but not $\mathrm{Ca}(\mathrm{V}) \mathbf{1 . 2}$ results in a diminished SAHP in mouse CA1 pyramidal neurons. Hippocampus, 21, 133-41.

25. Altman J, Das GD. (1965) Autoradiographic and histological evidence of postnatal hippocampal neurogenesis in rats. J Comp Neurol, 124, 319-35.

26. Kuhn HG, Dickinson-Anson H, Gage FH. (1996) Neurogenesis in the dentate gyrus of the adult rat: age-related decrease of neuronal progenitor proliferation. J Neurosci, 16, 202733.

27. Eriksson PS, Perfilieva E, Bjork-Eriksson T, Alborn AM, Nordborg C, Peterson DA, Gage FH. (1998) Neurogenesis in the adult human hippocampus. Nat Med, 4, 1313-7. 
28. Spalding KL, Bergmann O, Alkass K, Bernard S, Salehpour M, Huttner HB, Bostrom E, Westerlund I, Vial C, Buchholz BA, Possnert G, Mash DC, Druid H, Frisen J. (2013) Dynamics of hippocampal neurogenesis in adult humans. Cell, 153, 1219-27.

29. Clelland CD, Choi $M$, Romberg $C$, Clemenson GD, Jr., Fragniere A, Tyers $P$, Jessberger $S$, Saksida LM, Barker RA, Gage FH, Bussey TJ. (2009) A functional role for adult hippocampal neurogenesis in spatial pattern separation. Science, 325, 210-3.

30. Sahay A, Scobie KN, Hill AS, O'Carroll CM, Kheirbek MA, Burghardt NS, Fenton AA, Dranovsky A, Hen R. (2011) Increasing adult hippocampal neurogenesis is sufficient to improve pattern separation. Nature, 472, 466-70.

31. Aigner L, Bogdahn U. (2008) TGF-beta in neural stem cells and in tumors of the central nervous system. Cell Tissue Res, 331, 225-41.

32. Kandasamy M, Lehner B, Kraus S, Sander PR, Marschallinger J, Rivera FJ, Trumbach D, Ueberham U, Reitsamer HA, Strauss O, Bogdahn U, Couillard-Despres S, Aigner L. (2014) TGF-beta signalling in the adult neurogenic niche promotes stem cell quiescence as well as generation of new neurons. J Cell Mol Med, 18, 1444-59.

33. Korosi A, Naninck EF, Oomen CA, Schouten M, Krugers H, Fitzsimons C, Lucassen PJ. (2012) Early-life stress mediated modulation of adult neurogenesis and behavior. Behav Brain Res, 227, 400-9.

34. Fabel K, Kempermann G. (2008) Physical activity and the regulation of neurogenesis in the adult and aging brain. Neuromolecular Med, 10, 59-66.

35. Deisseroth K, Singla S, Toda H, Monje M, Palmer TD, Malenka RC. (2004) Excitationneurogenesis coupling in adult neural stem/progenitor cells. Neuron, 42, 535-52.

36. D'Ascenzo M, Piacentini R, Casalbore P, Budoni M, Pallini R, Azzena GB, Grassi C. (2006) Role of L-type Ca2+ channels in neural stem/progenitor cell differentiation. Eur J Neurosci, 23, 935-44.

37. Lepski G, Jannes CE, Nikkhah G, Bischofberger J. (2013) CAMP promotes the differentiation of neural progenitor cells in vitro via modulation of voltage-gated calcium channels. Front Cell Neurosci, 7, 155.

38. Teh DB, Ishizuka T, Yawo H. (2014) Regulation of later neurogenic stages of adult-derived neural stem/progenitor cells by L-type Ca channels. Dev Growth Differ.

39. Darcy DP, Isaacson JS. (2009) L-type calcium channels govern calcium signaling in migrating newborn neurons in the postnatal olfactory bulb. J Neurosci, 29, 2510-8.

40. Hayashi K, Homma K, Wakino S, Tokuyama H, Sugano N, Saruta T, Itoh H. (2010) T-type Ca channel blockade as a determinant of kidney protection. Keio J Med, 59, 84-95.

41. Veng LM, Browning MD. (2002) Regionally selective alterations in expression of the alpha(1D) subunit ( $\mathrm{Ca}(\mathrm{v}) 1.3)$ of L-type calcium channels in the hippocampus of aged rats. Brain Res Mol Brain Res, 107, 120-7.

42. Rowe WB, Blalock EM, Chen KC, Kadish I, Wang D, Barrett JE, Thibault O, Porter NM, Rose GM, Landfield PW. (2007) Hippocampal expression analyses reveal selective association of immediate-early, neuroenergetic, and myelinogenic pathways with cognitive impairment in aged rats. J Neurosci, 27, 3098-110.

43. Branch SY, Sharma R, Beckstead MJ. (2014) Aging decreases L-type calcium channel currents and pacemaker firing fidelity in substantia nigra dopamine neurons. J Neurosci, 34, 9310-8.

44. Platzer J, Engel J, Schrott-Fischer A, Stephan K, Bova S, Chen H, Zheng H, Striessnig J. (2000) Congenital deafness and sinoatrial node dysfunction in mice lacking class $D$ L-type Ca2+ channels. Cell, 102, 89-97.

45. Satheesh SV, Kunert K, Ruttiger L, Zuccotti A, Schonig K, Friauf E, Knipper M, Bartsch D, Nothwang HG. (2012) Retrocochlear function of the peripheral deafness gene Cacna1d. Hum Mol Genet, 21, 3896-909.

46. Vogel-Ciernia A, Matheos DP, Barrett RM, Kramar EA, Azzawi S, Chen Y, Magnan CN, Zeller M, Sylvain A, Haettig J, Jia Y, Tran A, Dang R, Post RJ, Chabrier M, Babayan AH, Wu JI, 
Crabtree GR, Baldi P, Baram TZ, Lynch G, Wood MA. (2013) The neuron-specific chromatin regulatory subunit BAF53b is necessary for synaptic plasticity and memory. Nat Neurosci, 16, 552-61.

47. Sah A, Schmuckermair C, Sartori SB, Gaburro S, Kandasamy M, Irschick R, Klimaschewski L, Landgraf R, Aigner L, Singewald N. (2012) Anxiety- rather than depression-like behavior is associated with adult neurogenesis in a female mouse model of higher trait anxiety- and comorbid depression-like behavior. Transl Psychiatry, 2, e171.

48. Morton RA, Norlin MS, Vollmer CC, Valenzuela CF. (2013) Characterization of L-type voltage-gated $\mathrm{Ca}(2+)$ channel expression and function in developing $\mathrm{CA} 3$ pyramidal neurons. Neuroscience, 238, 59-70.

49. Cai J, Cheng A, Luo Y, Lu C, Mattson MP, Rao MS, Furukawa K. (2004) Membrane properties of rat embryonic multipotent neural stem cells. J Neurochem, 88, 212-26.

50. Park HW, Jung H, Choi KH, Baik JH, Rhim H. (2010) Direct interaction and functional coupling between voltage-gated CaV1.3 $\mathrm{Ca2}+$ channel and GABAB receptor subunit 2. FEBS Lett, 584, 3317-22.

51. Song J, Zhong C, Bonaguidi MA, Sun GJ, Hsu D, Gu Y, Meletis K, Huang ZJ, Ge S, Enikolopov G, Deisseroth K, Luscher B, Christian KM, Ming GL, Song H. (2012) Neuronal circuitry mechanism regulating adult quiescent neural stem-cell fate decision. Nature, 489, 150-4.

52. Hsieh J, Schneider JW. (2013) Neuroscience. Neural stem cells, excited. Science, 339, 15345.

53. Kraus S, Lehner B, Reichhart N, Couillard-Despres S, Wagner K, Bogdahn U, Aigner L, Strauss O. (2013) Transforming growth factor-beta1 primes proliferating adult neural progenitor cells to electrophysiological functionality. Glia, 61, 1767-83.

54. Jaskova K, Pavlovicova M, Lichvarova L, Lacinova L. (2014) Transforming growth factor beta 1 differently affects molecular and electrophysiological properties of cerebellar granule cells and hippocampal neurons. . In: FENS Forum 2014, Milan, Italy.

55. Kadish I, Thibault O, Blalock EM, Chen KC, Gant JC, Porter NM, Landfield PW. (2009) Hippocampal and cognitive aging across the lifespan: a bioenergetic shift precedes and increased cholesterol trafficking parallels memory impairment. J Neurosci, 29, 1805-16.

56. Nunez-Santana FL, Oh MM, Antion MD, Lee A, Hell JW, Disterhoft JF. (2014) Surface L-type $\mathrm{Ca2+}$ channel expression levels are increased in aged hippocampus. Aging Cell, 13, 111-20.

57. Villeda SA, Luo J, Mosher KI, Zou B, Britschgi M, Bieri G, Stan TM, Fainberg N, Ding Z, Eggel A, Lucin KM, Czirr E, Park JS, Couillard-Despres S, Aigner L, Li G, Peskind ER, Kaye JA, Quinn JF, Galasko DR, Xie XS, Rando TA, Wyss-Coray T. (2011) The ageing systemic milieu negatively regulates neurogenesis and cognitive function. Nature, 477, 90-4.

58. Couillard-Despres S, Iglseder B, Aigner L. (2011) Neurogenesis, cellular plasticity and cognition: the impact of stem cells in the adult and aging brain--a mini-review. Gerontology, 57, 559-64.

59. Daschil N, Geisler S, Obermair GJ, Humpel C. (2014) Short- and long-term treatment of mouse cortical primary astrocytes with beta-amyloid differentially regulates the mRNA expression of L-type calcium channels. Pharmacology, 93, 24-31.

60. $\mathrm{Xu} \mathrm{JH}$, Long L, Tang YC, Hu HT, Tang FR. (2007) $\mathrm{Ca}(\mathrm{v}) 1.2, \mathrm{Ca}(\mathrm{v}) 1.3$, and $\mathrm{Ca}(\mathrm{v}) 2.1$ in the mouse hippocampus during and after pilocarpine-induced status epilepticus. Hippocampus, 17, 235-51.

61. Miller BR, Hen R. (2014) The current state of the neurogenic theory of depression and anxiety. Curr Opin Neurobiol, 30C, 51-58.

62. Couillard-Despres S, Wuertinger C, Kandasamy M, Caioni M, Stadler K, Aigner R, Bogdahn $\mathrm{U}$, Aigner L. (2009) Ageing abolishes the effects of fluoxetine on neurogenesis. Mol Psychiatry, 14, 856-64.

63. Rotheneichner $P$, Lange $S$, O'Sullivan A, Marschallinger J, Zaunmair P, Geretsegger $C$, Aigner L, Couillard-Despres S. (2014) Hippocampal neurogenesis and antidepressive therapy: shocking relations. Neural Plast, 2014, 723915. 
64. Cryan JF, Mombereau C. (2004) In search of a depressed mouse: utility of models for studying depression-related behavior in genetically modified mice. Mol Psychiatry, 9, 32657.

65. Scobie KN, Hall BJ, Wilke SA, Klemenhagen KC, Fujii-Kuriyama Y, Ghosh A, Hen R, Sahay A. (2009) Kruppel-like factor 9 is necessary for late-phase neuronal maturation in the developing dentate gyrus and during adult hippocampal neurogenesis. J Neurosci, 29, 9875-87.

66. Tronel S, Fabre A, Charrier V, Oliet SH, Gage FH, Abrous DN. (2010) Spatial learning sculpts the dendritic arbor of adult-born hippocampal neurons. Proc Natl Acad Sci U S A, 107, 7963-8.

67. Creer DJ, Romberg C, Saksida LM, van Praag H, Bussey TJ. (2010) Running enhances spatial pattern separation in mice. Proc Natl Acad Sci U S A, 107, 2367-72.

68. Clark NC, Nagano N, Kuenzi FM, Jarolimek W, Huber I, Walter D, Wietzorrek G, Boyce S, Kullmann DM, Striessnig J, Seabrook GR. (2003) Neurological phenotype and synaptic function in mice lacking the CaV1.3 alpha subunit of neuronal L-type voltage-dependent Ca2+ channels. Neuroscience, 120, 435-42.

69. Brimblecombe KR, Gracie CJ, Platt NJ, Cragg SJ. (2015) Gating of dopamine transmission by calcium and axonal $\mathrm{N}-, \mathrm{Q}-, \mathrm{T}$ - and L-type voltage-gated calcium channels differs between striatal domains. J Physiol, 593, 929-46.

70. Surmeier DJ, Guzman JN, Sanchez-Padilla J, Schumacker PT. (2011) The role of calcium and mitochondrial oxidant stress in the loss of substantia nigra pars compacta dopaminergic neurons in Parkinson's disease. Neuroscience, 198, 221-31.

71. Chiu WH, Depboylu C, Hermanns G, Maurer L, Windolph A, Oertel WH, Ries V, Hoglinger GU. (2015) Long-term treatment with L-DOPA or pramipexole affects adult neurogenesis and corresponding non-motor behavior in a mouse model of Parkinson's disease. Neuropharmacology, 95, 367-76.

72. Yang P, Arnold SA, Habas A, Hetman M, Hagg T. (2008) Ciliary neurotrophic factor mediates dopamine D2 receptor-induced CNS neurogenesis in adult mice. J Neurosci, 28, 2231-41.

73. Hoglinger GU, Rizk P, Muriel MP, Duyckaerts C, Oertel WH, Caille I, Hirsch EC. (2004) Dopamine depletion impairs precursor cell proliferation in Parkinson disease. Nat Neurosci, 7, 726-35.

74. Borta A, Hoglinger GU. (2007) Dopamine and adult neurogenesis. J Neurochem, 100, 58795.

75. Anekonda TS, Quinn JF. (2011) Calcium channel blocking as a therapeutic strategy for Alzheimer's disease: the case for isradipine. Biochim Biophys Acta, 1812, 1584-90.

76. Kang S, Cooper G, Dunne SF, Dusel B, Luan CH, Surmeier DJ, Silverman RB. (2012) CaV1.3selective L-type calcium channel antagonists as potential new therapeutics for Parkinson's disease. Nat Commun, 3, 1146.

\section{Figure Legends}

Figure 1. Cav1.2 expressionwithin theneurogenic regions of adult and middle-aged mice. (a) qRT-PCR analysis of Cav1.2 mRNA expression in different brain regions of 3-month and 15month old WT mice. In both age groups, Cav1.2 expression levels were similar in the hippocampus and cortex. In the 15-month age groups, Cav1.2 expression levels in the SVZ 
were decreased compared to the hippocampus. No age-related differences in mRNA expression levels were detected ( $n=3$ mice/age-group).(b,c) Intense Cav1.2 antibody staining was detected in the hippocampus (b) and in the SVZ (c) of adultand middle-aged mice. (d-g) Cav1.2 immunoreactivity in the dentate gyrus of adult mice. Cav1.2 signal was absent from Nestin ${ }^{+}$SCs (d) and from $\mathrm{DCX}^{+}$neuronal progenitors within the subgranular zone (e). In contrast, many $\mathrm{DCX}^{+}$immature neurons located in the granular zone (e), the majority of $\mathrm{NeuN}^{+}$granular neurons (f), and some GFAP ${ }^{+}$astrocytes (g) were positive for Cav1.2. (h-k) In the SVZ, Cav1.2 signal was absent from $\operatorname{Nestin}^{+}(\mathrm{h})$ and from $\mathrm{DCX}^{+}$cells (i), but colocalized with $\mathrm{NeuN}^{+}$neurons (j) and with some $\mathrm{GFAP}^{+}$astrocytes (k). Arrows indicate Cav1.2 co-localization, arrowheads point towards cells absent of Cav1.2 immunoreactivity. Scale bars: $200 \mu \mathrm{m}$ (b,c), $50 \mu \mathrm{m}$ (d-k). One-way ANOVA with Bonferroni post hoc tests was performed.

Figure 2. Cav1.3 is expressed within the neurogenic regions of adult and middle-aged mice. (a) qRT-PCR analysis of Cav1.3 mRNA levels in brain regions of 3-month and 15-month old WT mice. Cav1.3 mRNA levels were similar in the cortex, hippocampus and SVZ.Expression levels were not affected by age. (b-k) EGFP signal in adult (2-month) and middle-aged (15month)heterozygous Cacna1d-eGFP ${ }^{f l e x}$ mice indicates Cav1.3 expression.While GFP expression was similar between age-groups in the SVZ (c), in the hippocampal dentate gyrus the GFP signal was more intense in the granular cell layer (arrows) of middle-aged compared to adult mice (b). (d-g) In the dentate gyrus of 2-month old mice, EGFP signal was localized to Nestin ${ }^{+} \mathrm{NSCs}(\mathrm{d})$, to $\mathrm{NeuN}^{+}$mature neurons (f), and to some GFAP ${ }^{+}$astrocytes (g). Only a small fraction of $\mathrm{DCX}^{+}$cells was positive for EGFP (e). (h-k) In the SVZ of 2-month old mice, EGFP expression was observed in Nestin ${ }^{+} \mathrm{NSCs}(\mathrm{h})$, in a few $\mathrm{DCX}^{+}$neuronal progenitors (i), in $\mathrm{NeuN}^{+}$neurons (j) and in some $\mathrm{GFAP}^{+}$astrocytes (k). Arrows indicate EGFP colocalization, arrowheads point towards cells absent of EGFP signal. Scale bars: $200 \mu \mathrm{m}$ (b,c), $50 \mu \mathrm{m}(\mathrm{d}-\mathrm{k})$. One-way ANOVA with Bonferroni post hoc tests was performed. 
Figure 3. Neurogenesis is decreased in the dentate gyrus (DG) of adult and middle-aged Cav1.3/- mice. (a) DG volume is significantly decreased in 3-month and 15-month old Cav1.3/- mice compared to age-matched WT. (b) $\mathrm{PCNA}^{+}$cell numbers are similar between genotypes in 3-month old mice, but are significantly lower in 15-month old Cav1.3 ${ }^{-/-}$mice compared to age-matched WT. (c) Numbers of Nestin ${ }^{+}$cells were significantly reduced in 3month old Cav1.3 $3^{-/}$mice compared to WT, but were unchanged within the 15 -month age group. (d) $D C X^{+}$cell numbers were similar between genotypes within both age groups. (e) The amount of $\mathrm{BrdU}^{+}$cells, reflecting the surviving portion of cells newly generated four weeks before sacrifice, was significantly reduced in 3- and 15 -month old Cav1.3 $3^{-/-}$mice compared to age-matched WT. (f) Cell fate of newly generated cells within the DG. The percentage of newly generated $\mathrm{BrdU}^{+}$cells that have differentiated into neurons $\left(\mathrm{BrdU}^{+} / \mathrm{NeuN}^{+}\right)$was clearly reduced in 3-month old Cav1.3 ${ }^{--}$mice compared to age-matched WT, whereas the fraction of newly generated astrocytes $\left(\mathrm{BrdU}^{+} / \mathrm{GFAP}^{+}\right)$was similar (each pie represents $100 \%$ of $\mathrm{BrdU}^{+}$cells). (g) Total numbers of newly generated $\mathrm{NeuN}^{+}$neurons and $\mathrm{GFAP}^{+}$astrocytes reveal that in the 3-month age group, Cav1.3 ${ }^{-/-}$mice generated significantly fewer neurons than WT mice. (h) Representative images of GFAP immunolabeling in the DG of 3- and 15-month old Cav1.3 ${ }^{-/}$and WT mice. (i) GFAP ${ }^{+}$area was significantly decreased in the SGZ/GZin 3-month old Cav1.3--mice compared to age-matched WT. (j) 15-month old mice showed comparable $\mathrm{GFAP}^{+}$area within different regions of the DG (SGZ/GZsubgranular/granular zone; $M L$ molecular layer). $n=10$ mice/ young age group; $n=5$ mice/ middle-aged age group. Two-way ANOVA with Bonferroni post hoc tests were performed. (a-e) \# indicates significant differences $(P<0.05)$ between age-groups in WT mice. Scale bars: $100 \mu \mathrm{m}$.

Figure 4. Performance of adult Cav1.3 $3^{-/-}$mice in hippocampus-dependent tests for memory and anhedonia. 
(a) Sucrose preference test. Over a five week-period with increasing sucrose concentrations $(0.5 \%, 0.6 \%, 0.75 \%$ and $1 \%), \mathrm{Cav}_{1.3^{--}}$and WT mice showed similar, concentration dependent increasing preference for sucrose containing water over plain drinking water. (b) Object location memory test. Cav1.3 $3^{-/}$mice exhibited a significantly impaired object location discrimination index compared to WT mice. $n=10$ mice/group. Two-way ANOVA (a) and the Student's t-test (b) were performed. 


\section{Supplementary Material}

Supplementary Figure 1. NPCs derived from the hippocampus of adult Cav1.3 $3^{-/-}$mice and from WT mice show similar properties in vitro. (a) Representative images of neurospheres from freshly isolated hippocampal NPCs (passage 0) derived from WT and Cav1.3/- mice. Numbers (b) and volumes (c) of neurospheres (passage 0) did not differ between Cav1.3.and WT derived NPCs. (d) MTS assay analysis revealed no differences in cell proliferation

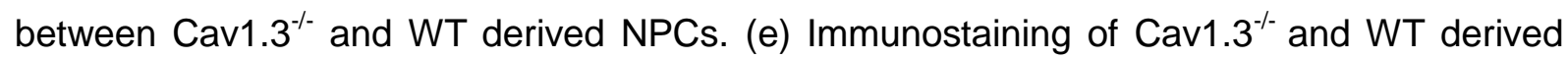
NPCs after one week of growth factor withdrawal exhibits no differences in the morphology of Map2ab ${ }^{+}$neurons and GFAP ${ }^{+}$astrocytes between genotypes. (f) The frequency of Map2ab ${ }^{+}$ and $\mathrm{GFAP}^{+}$expressing cells after one week of growth factor withdrawal was similar between Cav1.3/- and WT derived hippocampal NPCs. Three independent experiments were done in triplicates. $n=5 /$ group. The Student's t-test $(b, c, d)$ and Two-way ANOVA with Bonferroni post hoc tests (f) were performed. Scale bars: $50 \mu \mathrm{m}$.

\section{Supplementary Methods}

\section{Adult mouse neurosphere cultures}

Neurosphere cultures from hippocampi of 4-month old female Cav1.3 $3^{-1-}$ mice and WT mice ( $n=5 /$ group) were obtained as described previously $\{$ Wachs, $2003 \# 45\}$. Briefly, mice were decapitated and hippocampi were aseptically removed and dissociated. Cells were resuspended separately for each animal in Neurobasal-A (NB-A) medium (Gibco BRL) supplemented with B27 (Gibco BRL), 2 mM L-glutamine (PAN), $100 \mathrm{U} / \mathrm{ml}$ penicillin/0.1 mg/l streptomycin (PAN), hereafter referred to as NB/B27. For maintenance and expansion of the cultures, the NB-A/B27 was further supplemented with $2 \mathrm{mg} / \mathrm{ml}$ heparin (Sigma), $20 \mathrm{ng} / \mathrm{ml}$ FGF-2 (R\&D Systems) and $20 \mathrm{ng} / \mathrm{ml}$ EGF (R\&D Systems). Cells were seeded in T-25 culture flasks, grown in suspension cultures at $37^{\circ} \mathrm{C}$ in an incubator with $5 \% \mathrm{CO}_{2}$ and passaged 
weekly. For dissociation, spheres were incubated with Accutase (Innovative Cell Technologies Inc.) for $10 \mathrm{~min}$ at $37^{\circ} \mathrm{C}$ and triturated using a pipette before being resuspended in NB medium. Cell number was determined by Trypan blue exclusion and $5 \times 10^{4}$ cells/ $\mathrm{ml}$ were plated in new T75 culture flasks in NB medium. Cells of passage numbers 2 to 6 were used for MTS-Assay and cell differentiation experiments. P0 neurosphere size and number analysis:

To determine the numbers and sizes of neurospheres from passage 0 , six randomly selected fields per T-25 culture flask were photographed four days after initial NPC seeding. Numbers of spheres were counted and their diameters were assessed. From the spheres' diameters, single sphere volumes were calculated and further used for calculation the total volume of all spheres in one flask.

\section{Analysis of cell proliferation - MTS-Assay}

After passaging, cells were seeded in 96 -well culture plates at a concentration of $5 \times 10^{4}$ cells/ml in a volume of $100 \mu \mathrm{l}$ NB/B27 medium containing a reduced EGF and FGF concentration of $5 \mathrm{ng} / \mathrm{ml}$. The plates were then maintained at $37^{\circ} \mathrm{C}$ in a humidified incubator (Heraeus) with $5 \% \mathrm{CO}_{2}$ for 7 days. $10 \mu \mathrm{l}$ of NB-Medium was added on days 2 and 6 . At day 7, proliferation was assessed using an MTS assay kit (CellTiter 96 AQueous One Solution Cell Proliferation Assay, Promega) according to the manufacturer's instructions. After $4 \mathrm{~h}$ of incubation, optical density was measured at $490 \mathrm{~nm}$ using a plate reader (Emax Precision Microplate Reader, Molecular Devices).

NPC differentiation:

In order to analyze the differentiation fate of neurospheres derived from Cav1.3 $3^{-/}$and wildtype mice, NPCs were plated on poly-ornithine- $(100 \mu \mathrm{g} / \mathrm{ml})$ and laminin- $(5 \mu \mathrm{g} / \mathrm{ml})$ coated (Sigma) glass coverslips at a density of $25.000 \mathrm{cells} / \mathrm{cm}^{2}$, incubated in NB-A/B27 medium without any growth factors for 7 days, fixed for 30 min with $4 \%$ paraformaldehyde and processed for immunofluorescence. 


\section{Immunocytochemistry}

For immunocytochemical analysis, cells were washed in TBS $(0.15 \mathrm{M} \mathrm{NaCl}, 0.1 \mathrm{M}$ Tris- $\mathrm{HCl}$, $\mathrm{pH}$ 7.5), then blocked with a solution composed of TBS, $1 \%$ bovine serum albumin (BSA) and $0.2 \%$ Teleostean gelatin (Sigma). The same solution was used during the incubations with antibodies. Primary antibodies were applied overnight at $4^{\circ} \mathrm{C}$. Fluorochrome-conjugated species-specific secondary antibodies were used for immunodetection. The following antibodies and final dilutions were used. Primary antibodies: mouse anti-Map2ab (1:250, Promega), rabbit anti-GFAP (1:1000, Progen). Secondary antibodies: donkey anti-rabbit Alexa 488, donkey-anti mouse Alexa 647 (all 1:1000, Invitrogen). Nuclear counterstaining was performed with 4', 6'-diamidino-2- phenylindole dihydrochloride hydrate at $0.25 \mu \mathrm{g} / \mu \mathrm{l}$ (DAPI; Sigma). Specimens were mounted on microscope slides using a Prolong Antifade kit (Molecular Probes). Epifluorescence observation was performed using an Olympus IX81 (Olympus) equipped with Hamamatsu digital camera and Volocity software (Perkin Elmer). For each culture condition, 10 randomly selected observation fields, containing in total 250500 cells, were photographed for cell fate analysis. Expression frequency of selected cell type markers was determined for every condition in three independent experiments. 
Figure 1
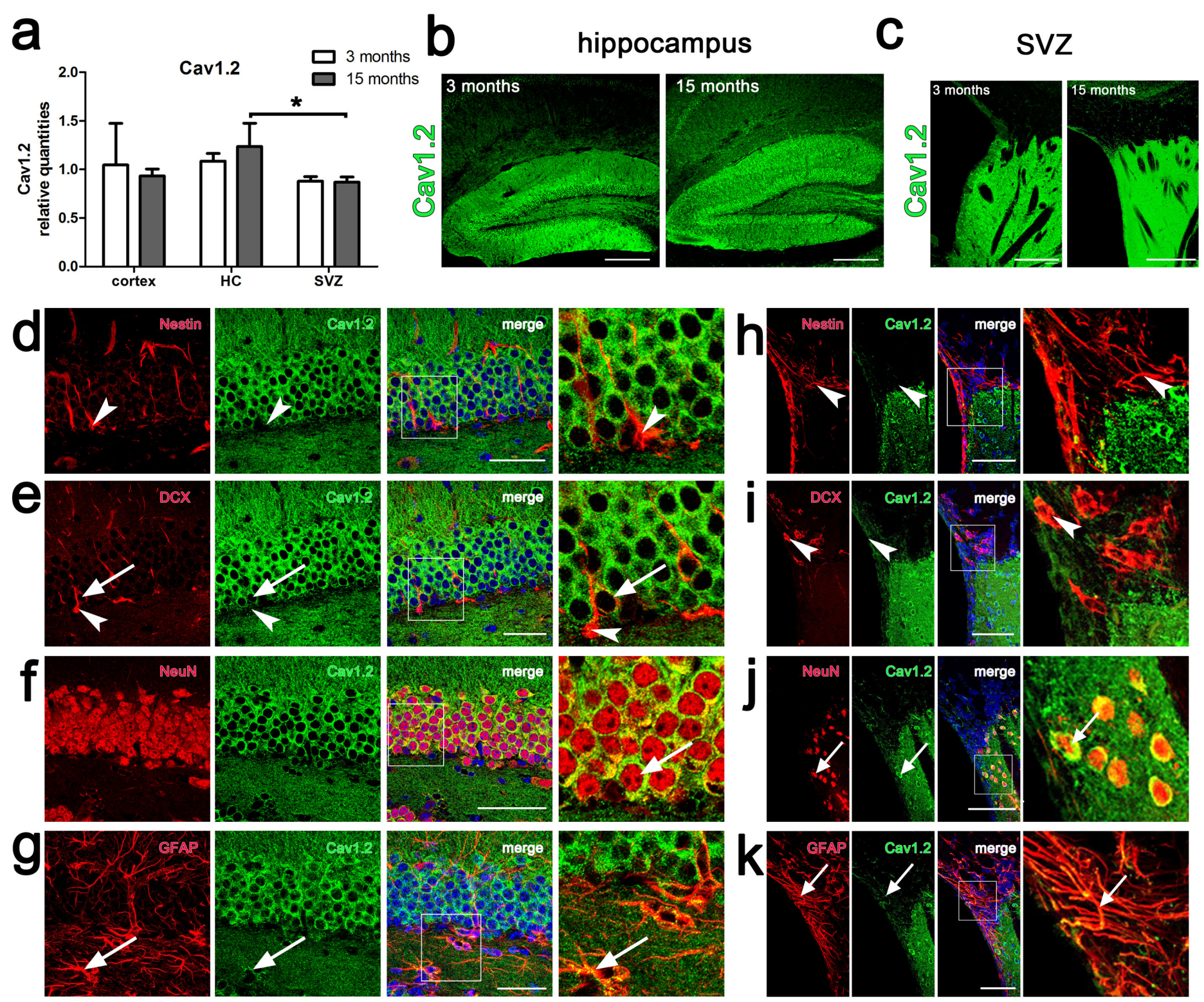
Figure 2
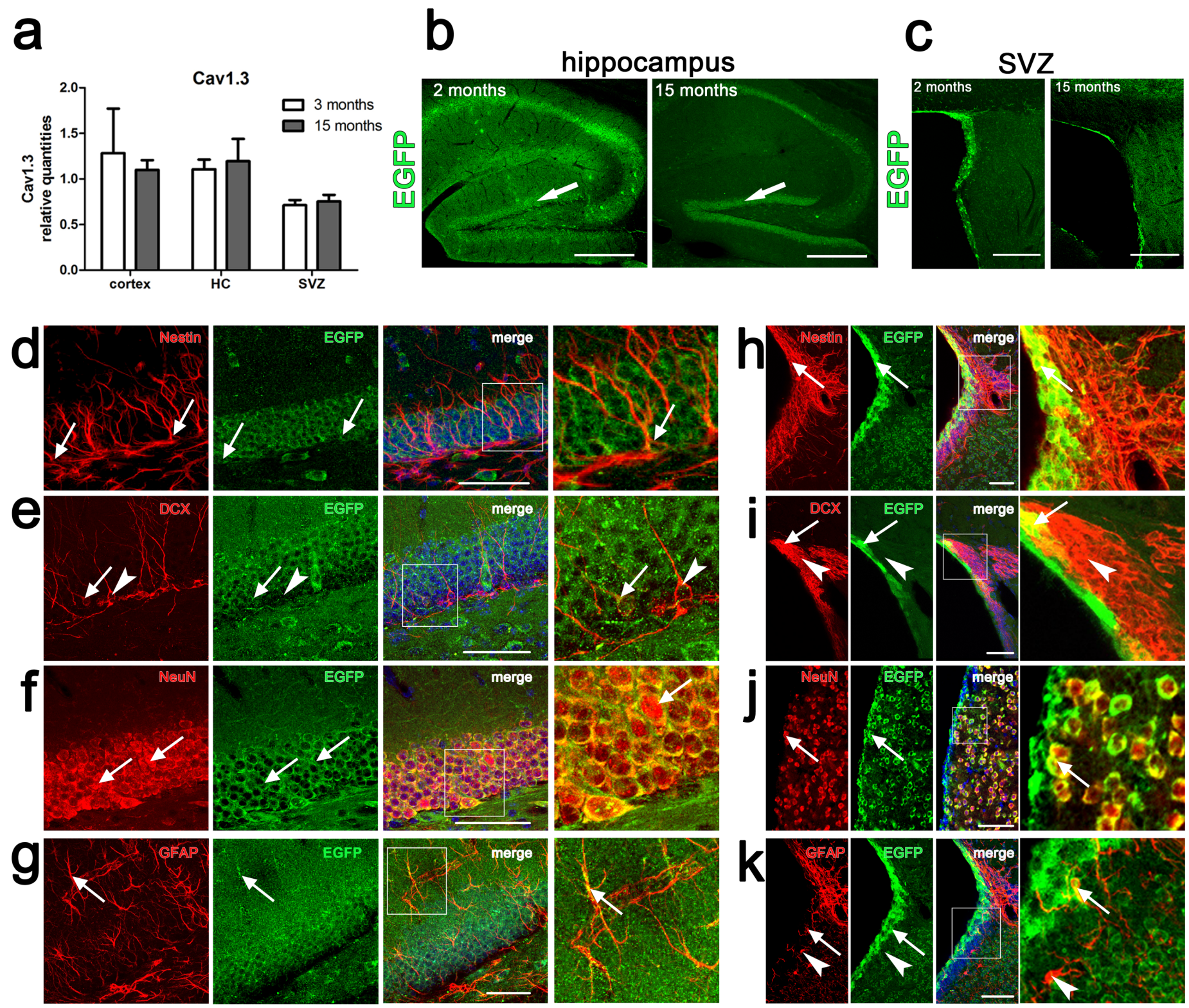
Figure 3

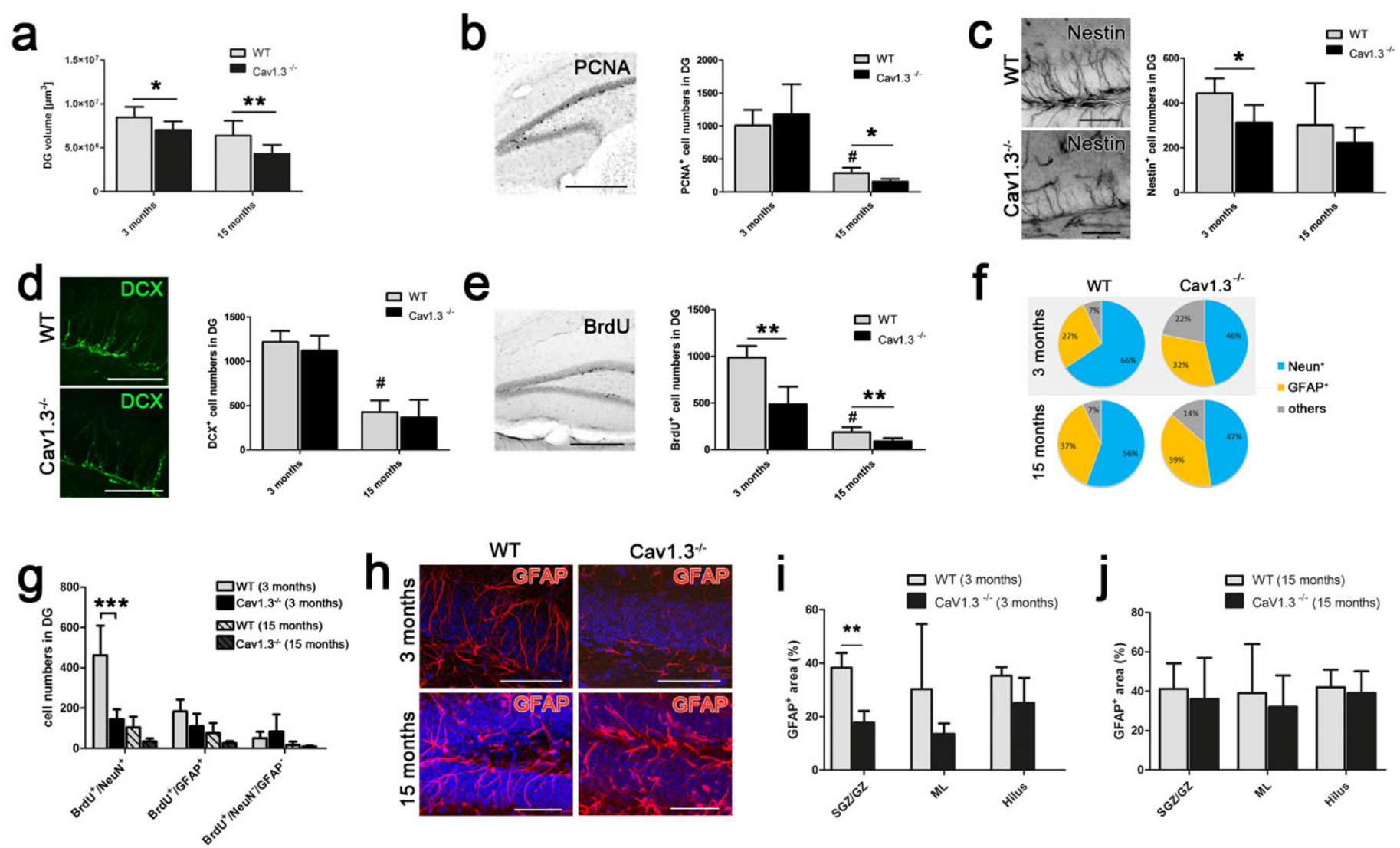




\section{Figure 4}

a

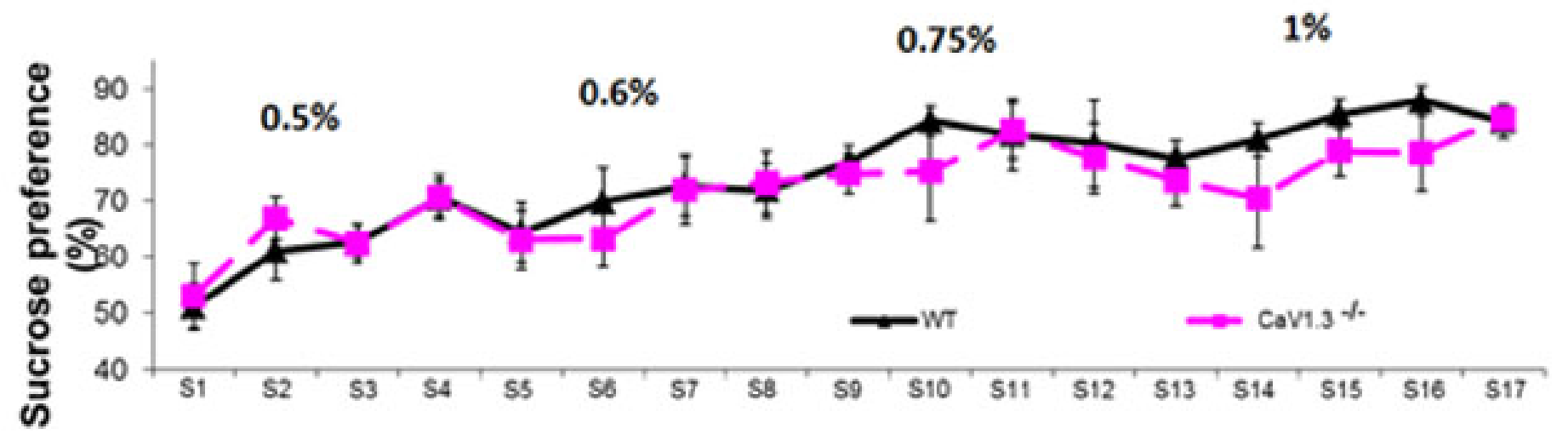

b

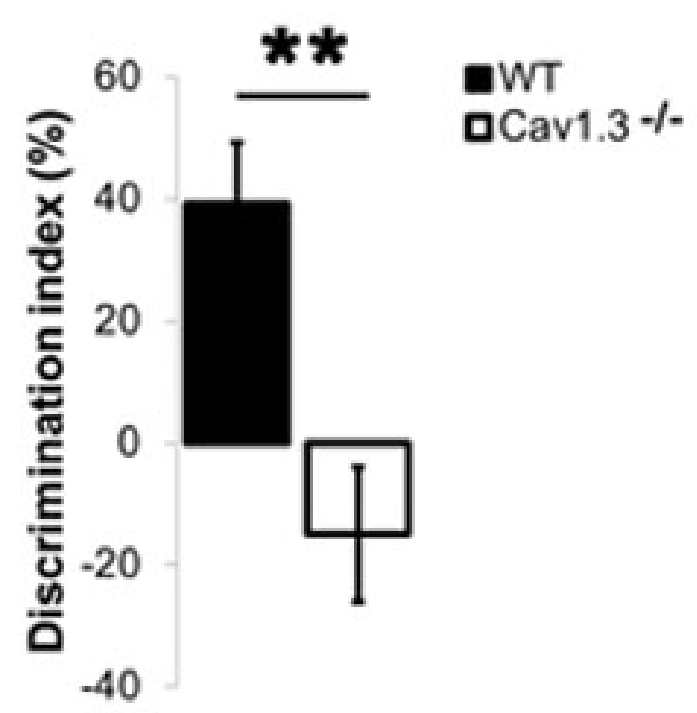




\section{Supplementary Figure 1}

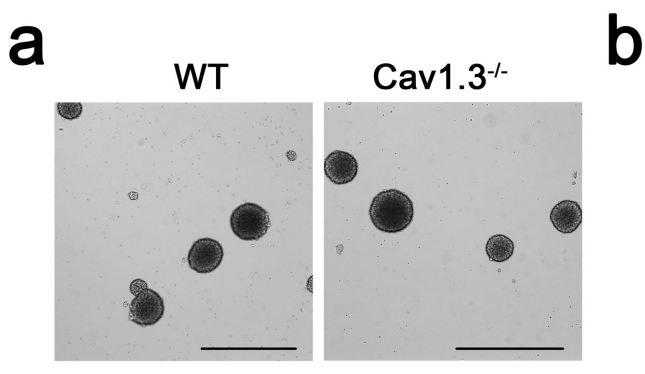

b

C
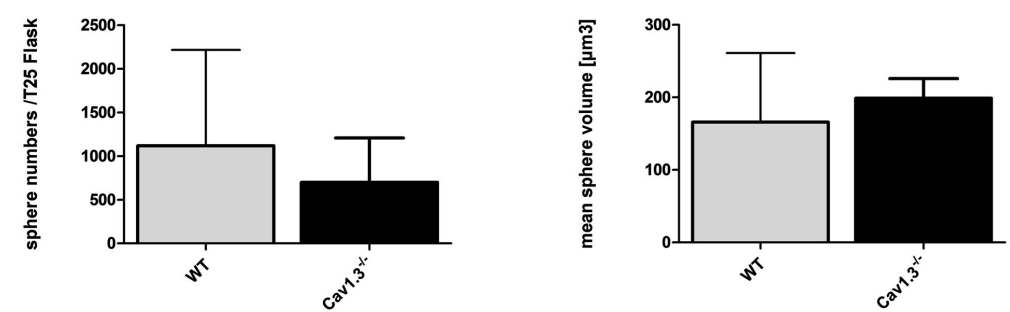

d

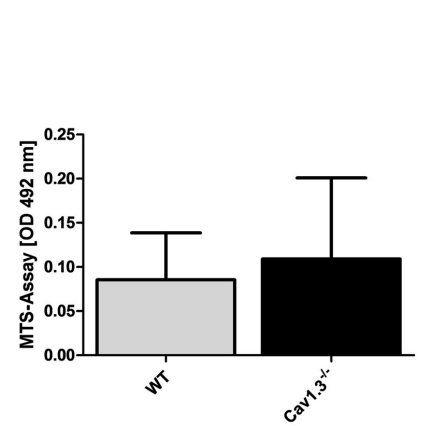

e

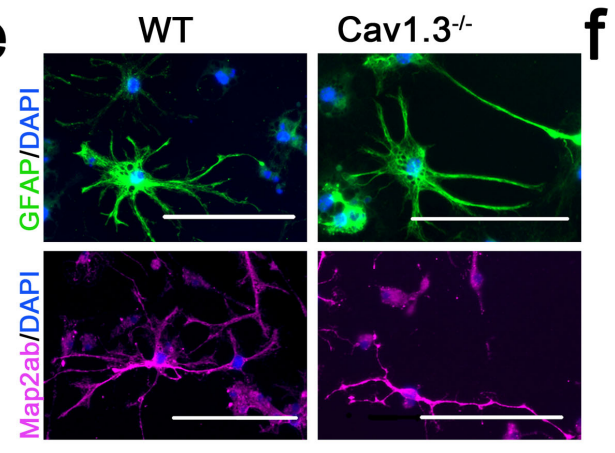

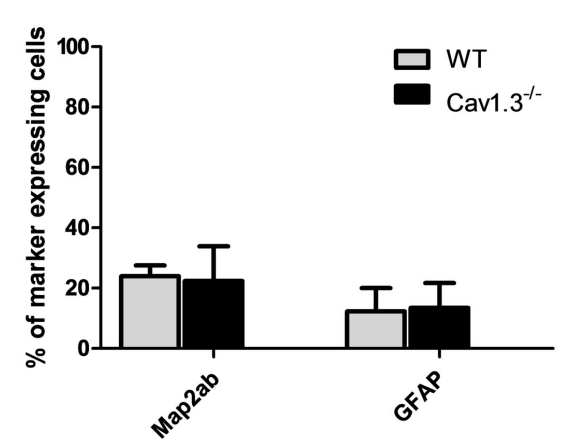

